\title{
New working conditions and consequences on activity of home healthcare workers
}

\author{
Corinne Van De Weerdt ${ }^{\mathrm{a}^{*}}$ and René Baratta ${ }^{\mathrm{b}}$ \\ a Preventive Ergonomics and Psychology Laboratory, Working Life Department, INRS, 1 rue Morvan, CS 60027, \\ 54519 Vandoeuvre cedex, France. \\ ${ }^{\mathrm{b}}$ L'ouvre Boîte, 20 rue Devéria, 75020, Paris, France.
}

\begin{abstract}
Home healthcare is steadily growing in Europe. There are a number of reasons for this development: aging population, rising hospital costs, preference to stay in one's own home. Nevertheless, it has been known that home healthcare workers are frequently exposed to a variety of potentially serious occupational hazards. Furthermore, emotional labor is frequently high in this profession. This paper describes an ergonomic study conducted at a home healthcare service. The research focuses on analyzing working conditions of home healthcare aides and nurses, as well as the impacts of their work in terms of job satisfaction, well-being, emotions at work, relationships with the others and occupational stress. The study show that employee strategies are specifically centered around preserving the relationship between patients and workers and coping with the job demands. This paper also shows that home healthcare workers express emotions and conceal them from others. Finally, recommendations discussed with the manager and workers to improve working conditions in this sector led to practical proposals: for example, implementing certain equipment items better suited to difficult care, encouraging assistance between healthcare workers when operations require this through adequate organizational measures, extending work emotion-focused discussion groups with management involvement.
\end{abstract}

Keywords: emotion, home healthcare, job satisfaction, occupational stress, workplace.

\section{Introduction}

Home healthcare is steadily growing in Europe; there are a number of reasons for this development. For example in France, an aging population has created new and increasing demand for an alternative form of healthcare and rising hospital costs have contributed to the expansion of new healthcare services. Furthermore, more and more people prefer to stay in their own home rather than to go to hospital or relocate to a family. There is a general tendency for people to preserve the greatest possible independence. Live-in home care is especially appropriate for a person suffering from Alzheimer's disease, for example, or for someone at risk of falling and being incapable of getting up from the floor alone or for someone who cannot remember to take medication. Home healthcare workers also facilitate quick, smooth transition of patients from a hospital to a home environ- ment and they provide patients with the opportunity of receiving quality medical care in the comfort of their own homes.

For several years, it has been known that home healthcare workers are frequently exposed to a variety of potentially serious hazards (El-Askari \& DeBaun, 1999). Recently, the NIOSH (2010) published a report describing a list of occupational risks, to which these workers are exposed. This list features psychosocial risks in addition to chemical and biological risks. For example, NIOSH refers to overexertion, verbal abuse, physical violence, stress at work. Burnout is also a very common phenomenon in these occupations (Estryn-Béhar \& al., 2007; Meissner \& al., 2007). Similarly, the European NEXT study of healthcare worker quality of life, conducted between 2004 and 2006, revealed the problems encountered by these workers, when performing their jobs their occupation prematurely. This is a major concern

\footnotetext{
*Corresponding author. Phone : +33(0)383508790, Fax : +33(0)383502182, E-mail: corinne@vandeweerdt@inrs.fr.
} 
since all ten countries covered by the study are affected.

Similarly, emotional labor is frequently high in this profession (Hochschild, 1983; Totterdell \& Holman, 2003). Workers are often required to deal with difficult situations in relation to the affective component of their occupation and they are increasingly exposed to high emotional demands. For example, a healthcare worker is sometimes required to conceal negative emotions relating to disease development in a patient, for whom he or she is caring, if recovery progress is in doubt. The intention is to avoid negatively influencing this patient's own emotions. Emotion contagiousness phenomena are strategically avoided by personnel in some circumstances, as shown by several researchers (Hatfield, Cacioppo \& Rapson, 1993; Barsade, 2002).

\section{Method}

This paper describes an ergonomic study conducted at a home healthcare service. Our approach was based on an ergonomic operation. Two study operators monitored 8 male nurses, 7 nursing aides, 3 coordinating nurses and 3 secretaries for a week using a video medium, when this was possible and accepted by the persons observed. Collective interviews were initially held by job group (disciplinary), followed by collective interviews involving different jobs (cross-disciplinary) (table 1). These sessions prompted discussion on working conditions and their potential improvement.

The research focuses on analyzing working conditions of home healthcare aides and nurses, as well as the impacts of their work in terms of job satisfaction, well-being, emotions at work, relationships with the others (patients, colleagues, managers, clinicians, directors, etc.) and occupational stress. This study is oriented to the activity, the emotional labor, the occupational stress in the workplace and the strategies adopted by employees to cope with these issues.

\section{Results}

Nurse and nursing aide activity involves administering patient care, while also responding to certain expectations that fall within the area of workerpatient relations. The activity is both technical and relational. The proportion of these two work dimensions varies, depending on not only the context, but also the patient and his/her characteristics. The technical portion is equal to the relation portion of the care, when everything happens as intended, without any unforeseen event delaying the worker's visits. But, technical performance will be favoured in the event of lateness. On the other hand, the most frequent situations are those in which the relationship is of prime importance to providing the care. For example, this is the case when a patient complains of pain, will not cooperate and resists by adopting a position that is inconvenient for the healthcare worker. The patient may also ask for repeated explanations in relation to the care operation or may need to receive calming words. In this case, relational activity will be favoured because it become essential before administering the medical dimension of the care. The time taken to perform relational operation will be longer than that related to the technical procedure.

The sequence of healthcare visits will then be structured based on these aspects to avoid accumulated delays with respect to the forecast schedule. Visit schedules are organised in advance by coordinating nurses, so adjustment by healthcare workers affects the work of the schedulers, who have to take this field adjustment into account. They need to adapt the visits scheduled for the future as best they can. Proper coordination and consideration of each person's constraints is fundamental to efficient operation of the structure. However, the total of visits and the time spent in car are high (table 2) and the work organisation for healthcare workers by coordinating nurses is difficult to perform. Here again, the relational aspect (internal to the organisation) play a major part.

Recognition of healthcare work's relational and affective dimension (between carers and patients and between carers and management personnel) is a key to success. Observed sources of stress are caused by confrontation between these requirements and between optimising the relationship and the speed of care to ensure all the scheduled visits.

Employee strategies are specifically centered around preserving the relationship (between patients and workers) and coping with the job demands. As a minimum, employees seek to work in line with the organization culture, while nurturing patient wellbeing and preserving their own health. 
Table 1

Number of observations and collective interviews.

\begin{tabular}{|c|c|}
\hline \multicolumn{1}{|c|}{ Number of observations } & Number of collective interviews \\
\hline$>\quad 4$ nurses - with video & $>\quad 3$ interviews - job group - with video \\
$>\quad 3$ nurses - without video (notes) & $>\quad 1$ interview - job group - without video (notes) \\
$>\quad 2$ nursing aides - with video & $>\quad 2$ interviews - different job group - with video \\
$>\quad 2$ nursing aides - without video (notes) & $>1$ interview - validation of the final video \\
\hline
\end{tabular}

Table 2

Time distribution between visits and routes of home healthcare workers.

\begin{tabular}{|c|c|c|c|c|c|}
\hline \multicolumn{3}{|c|}{ Nursing aides activity } & \multicolumn{3}{|c|}{ Nurses activity } \\
\hline \multirow[t]{3}{*}{ In the morning } & average time per visit & 32 minutes & \multirow[t]{3}{*}{ In the morning } & average time per visit & 6 minutes \\
\hline & average time spent in car & $\begin{array}{l}56 \text { minutes for } 5 \\
\text { working hours }\end{array}$ & & average time spent in car & $\begin{array}{l}75 \text { minutes for } 3 \\
\text { working hours }\end{array}$ \\
\hline & $\begin{array}{l}\text { average time between } 2 \\
\text { visits }\end{array}$ & 8 minutes & & $\begin{array}{l}\text { average time between } 2 \\
\text { visits }\end{array}$ & 6 minutes \\
\hline \multirow[t]{3}{*}{ In the evening } & average time per visit & 15 minutes & \multirow[t]{3}{*}{ In the evening } & average time per visit & 8 minutes \\
\hline & average time spent in car & $\begin{array}{l}65 \text { minutes for } 2,5 \\
\text { hours of work }\end{array}$ & & average time spent in car & $\begin{array}{c}107 \text { minutes for } 6 \\
\text { working hours }\end{array}$ \\
\hline & $\begin{array}{l}\text { average time between } 2 \\
\text { visits }\end{array}$ & 10 minutes & & $\begin{array}{l}\text { average time between } 2 \\
\text { visits }\end{array}$ & 8 minutes \\
\hline
\end{tabular}

Home healthcare workers express emotions and conceal them from others and, in this connection, emotional strategies are used in the workplace. In relation to emotional work, healthcare workers conceal some of their emotions from patients, but express them to their nursing or nursing aide colleagues in order to share them after their visits. These moments of emotion share take place after work because of the lack of time (table 2).

Positive emotions at work felt by healthcare workers are most often linked to regression of patient's disease, quality of their relationship with the patient, their feeling of helpfulness, success of technical procedures leading to less pain for the patient, the latter's acceptance of his/her state of health and the care administered and, finally, physical aspects such as car journey conditions, available equipment, etc.

Negative emotions at work are linked to a poor relationship with the patient, care performance conditions (lack of space, medical bed, hygiene, etc.), time-related pressure, which adversely affects relational activity and lack of constraint recognition by the management.

\section{Discussion}

The effectiveness of expounding and coping with problems, discussing emotional strategies, job satisfaction, and stress at work with the colleagues is real.

The efficiency in sharing emotions in an organization-based formal group led or controlled by management and managers is important in terms of recognizing the work's relational and affective dimension. It would indeed be fundamental to work-related dialogue, job satisfaction, social support, etc. Recent experience of this formal group had a positive effect in terms of occupational well-being. This group offered the possibility to employees to express and to share their emotions concerning a specific patient situation which can emotionally affect workers.

These exchanges involved a wider free emotions expression concerning a specific case, but also the recognition of the emotional and relational part of work by management. This formal group led by management, and the collective interviews conducted by researchers, allowed to increase the feeling of 
mutual trust and to recreate a favorable social climate to dialogue. They also had a positive effect in terms of motivation at work.

Finally, recommendations discussed with the manager and workers to improve working conditions in this sector led to practical proposals. For example, they enabled us to reveal the advantage of implementing certain equipment items better suited to difficult care (especially introducing winglets for injections that are particularly difficult to perform).

They also allowed us to favor and encourage assistance between healthcare workers, when operations require this (e.g. heavy patients) through adequate organizational measures.

Moreover, extending work emotion-focused discussion groups with management involvement provided not only psychological help for healthcare workers, but also management recognition of the work's affective dimension, which can be a burden to manage only by oneself and can cause health consequences when there is no support.

Working conditions could be improved through greater knowledge of work constraints in parallel with expression of encountered difficulties. This is a practical part of preventing occupational, including psychosocial, hazards.

\section{References}

[1] Barsade, S.G. (2002). The Ripple Effect: Emotional Contagion and its Influence on Group Behavior. Administrative Science Quarterly, 47, 644-675.

[2] El-Askari E, \& DeBaun B. (1999). The Occupational Hazards of Home Health Care. In: Charney W, Fragala G, editors. The epidemic of health care worker injury. Boca Raton, Florida: CRC Press., 201-13.

[3] Estryn-Béhar, M., Van der Heijden, B., Ogińska, H., Camerino, D, Le Nézet, O, Conway, P.M., Fry, C., Hasselhorn, H.M., NEXT Study Group. (2007). The impact of social work environment, teamwork characteristics, burnout, and personal factors upon intent to leave among European nurses. Medical Care, 45, 10, 939-50.

[4] Hatfield, E., Cacioppo, J. L. \& Rapson, R. L. (1993). Emotional contagion. Current Directions in Psychological Sciences, 2, 96-99.

[5] Hochschild, A. (1983). The managed heart: Commercialization of human feeling. Berkeley: University of California Press.

[6] Meissner A., Hasselhorn, H.M., Estryn-Behar, M., Nézet, O., Pokorski, J., Gould, D. (2007). Nurses' perception of shift handovers in Europe: results from the European Nurses' Early Exit Study. Journal of advanced nursing. 57, 5, 535-42.

[7] Niosh Hazard Review (2010). Occupational hazards in home healthcare. DHHS (NIOSH) Publication Number 2010-125, $55 \mathrm{p}$.
[8] Totterdell P, \& Holman D. (2003). Emotion regulation in customer service roles: Testing a model of emotional labor. Journal of Occupational Health Psychology, 8, 55-73. 